\title{
A Meir-Keeler type fixed point theorem in fuzzy metric spaces.
}

\author{
Siditë Duraj
}

Department of Mathematics; Faculty of Natural Sciences, University of Shkodra, Shkoder, Albania

siditaduraj@yahoo.com

\section{Elida Hoxha}

Department of Mathematics; Faculty of Natural Sciences, University of Tirana; Tirana, Albania hoxhaelida@yahoo.com

Abstract: In this paper we introduce a new definition of Meir-Keeler type contractions and prove a fixed point theorem for them in fuzzy metric space.

Keywords: Fuzzy metric space; fixed point theorem; Meir-Keeler type contraction.

\section{Academic Discipline and Sub-Disciplines}

Mathematics, Functional Analysis.

\section{SUBJECT CLASSIFICATION}

Functional Analysis

\section{Introduction.}

The introduction of the notion of a fuzzy set, is a new way to represent the vagueness in everyday life, by Zadeh [8] in 1965 and proves a turning point in the development of fuzzy mathematics. In 1975, Kramosi and Michalek [4] gave the notion of fuzzy metric spaces, which could be considered as a reformulation, in the fuzzy context, of the notion of probabilistic metric space due to Menger [7]

The Banach contraction principle is the most celebrated fixed point theorem. It is very useful, simple, and classical tool in nonlinear analysis. This principle has many generalizations. For example, in 1969 [2] Meir and Keeler proved a fixed point theorem for the mappings satisfying a $(\varepsilon-\delta)$ contractive condition. Some generalizations of Meir-Keeler fixed point theorem (see $9,5,6)$ established a class of the contractions called the Mier-Keeler type contraction.

Fixed point theory in fuzzy metric spaces has been developed starting with the work of Heilpern [12]. In [1] George and Veeramani introduced and studied the notion of fuzzy metric spaces which constitutes a modification of the one due Kramosil and Michalek. From now on, by fuzzy metric we mean a fuzzy metric in the sense of George and Veeramani. Many authors have contributed to the development of this theory.

In this paper we will introduce a new Meir-Keeler type contractive condition in fuzzy metric spaces and establish a fixed point theorem in fuzzy metric spaces by using this Meir- Keeler type contractive condition. Our theorem generalize, unify and extend many results in literature.

\section{Preliminaries.}

For convenience we start with the following definitions, lemmas, and theorems.

Definition 1. [1] A binary operation $*:[0,1] \times[0,1] \rightarrow[0,1]$ is a continuous t-norm if it satisfies the following conditions:

(i) * is commutative and associative;

(ii) $*$ is continuous;

(iii) $a * 1=a$ for all a $a \in[0,1]$;

(iv) $a * b \leq c * d$ whenever $a \leq c$ and $b \leq d$ for all $a, b, c, d \in[0,1]$.

Examples of t-norms are $a * b=a b, a * b=\min \{a, b\}$ and $a * b=\max \{a+b-1,0\}$.

Definition 2. [1] The 3-tuple $(X, M, *)$ is said to be a fuzzy metric space if $\mathrm{X}$ is an arbitrary set, $*$ is a continuous tnorm and $\mathrm{M}$ is a fuzzy set on $X^{2} \times[0, \infty$ [ satisfying the following conditions for all $x, y, z \in X$ and $\mathrm{s}, \mathrm{t}>0$ :

i) $M(x, y, 0)=0$

ii) $M(x, y, t)=1$ for all $\mathrm{t}>0$ if and only if $x=y$,

iii) $M(x, y, t)=M(y, x, t)$

iv) $M(x, y, t) * M(y, z, s) \leq M(x, z, t+s)$, 
v) $M(x, y, \cdot):[0, \infty[\rightarrow[0,1]$ is left continuous.

The function $M(x, y, t)$ denotes the degree of nearness between $\mathrm{x}$ and $\mathrm{y}$ with respect to t. So, we identify $M(x, y, t)=1$ with $x=y$ and $M(x, y, t)=0$ with $\infty$.

Lemma 3. [11]. $M(x, y, *)$ is nondecreasing for all $\mathrm{x}, \mathrm{y}$ in $\mathrm{X}$.

\section{Remarks 4. [1].}

(1). In a fuzzy metric space $(X, M, *)$, whenever $M(x, y, t)>1-r$ for $x, y \in X, t>0,0<r<1$, we can find a $0<t_{0}<t$ such that $M\left(x, y, t_{0}\right)>1-r$.

(2) For any $r_{1}>r_{2}$, we can find a $r_{3}$ such that $r_{1} * r_{3} \geq r_{2}$ and for any $r_{4}$, we can find a $r_{5}$ such that $r_{5} * r_{5} \geq r_{4}$ $\left(r_{1}, r_{2}, r_{3}, r_{4}, r_{5} \in(0,1)\right)$.

Example 5. [1] Let $X=\mathrm{R}$. Define $a * b=a b$ and $M(x, y, t)=\left[\exp \left(\frac{|x-y|}{t}\right)\right]^{-1}$ for all $x, y \in X, t>0$. Then $(X, M, *)$ is a fuzzy metric space.

Each fuzzy metric $(X, M, *)$ on $X$ generates a $T_{2}$-topology on $X$, which has as base the family of open balls $\{B(x, r, t): x \in X, r \in(0,1), t>0\}$, where $B(x, r, t)=\{y \in X ; M(x, y, t)>1-r\}$

Definition 6. [11] A sequence $\left\{x_{n}\right\}$ in a fuzzy metric space $(X, M, *)$ is said to be:

(i) a Cauchy sequence if for all $t>0$ and $p>0, \lim _{n \rightarrow \infty} M\left(x_{n+p}, x_{n}, t\right)=1$;

(ii) convergent to a point $x \in X$ if for all $t>0, \lim _{n \rightarrow \infty} M\left(x_{n}, x, t\right)=1$.

Notice that the limit of sequence in fuzzy metric space is unique.

Definition 7.[11] A fuzzy metric space $(X, M, *)$ is complete if and only if every Cauchy sequence in $\mathrm{X}$ is convergent.

Example 8. [10]. Let $X=\left\{\frac{1}{n}: n \in N\right\}$ and let $*$ be the continuous t-norm defined by $a * b=a b$ for all $a, b \in[0,1]$. For each $t>0$ and $x, y \in X$, define $(X, M, *)$ by $M(x, y, t)=\frac{t}{t+|x-y|} \quad$ and $M(x, y, 0)=0$. Clearly, $(X, M, *)$ is a complete fuzzy metric space.

Theorem 9. [2] ( Fixed point theorem of Meir-Keeler) Let $(X, d)$ be a metric space and let T be a mapping from $X$ into itself satisfying the following condition:

$\forall \varepsilon>0, \exists \delta(\varepsilon)>0$ such that $\varepsilon \leq d(x, y)<\varepsilon+\delta(\varepsilon) \Rightarrow \mathrm{d}(\mathrm{Tx}, \mathrm{Ty})<\varepsilon$

Then T has a unique fixed point $z \in X$. Moreover, for all $x \in X$, the sequence $\left\{T^{n} x\right\}$ converges to $z$.

A. Razani in [3] defined fuzzy $\varepsilon$-contractive mapping.

Definition 10. [3] . Let $(X, M, *)$ be a fuzzy metric space and $0<\varepsilon<1$. A mapping $T: X \rightarrow X$ is called fuzzy $\varepsilon$ contractive if $1-\varepsilon<M(x, y, t)<1 \Rightarrow M(T x, T y, t)>M(x, y, t)$

The following theorem has been proved by Razani in [3 (5)].

Theorem 11. [3]. Let $(X, M, *)$ be a complete fuzzy metric space, where the continuous t-norm is defined as $a * b=\min \{a, b\}$. Suppose $T: X \rightarrow X$ is a fuzzy $\varepsilon$-contractive, such that there exists a point $x \in X$ whose 
sequence of iterates $\left(T^{n} x\right)$ contains a convergent subsequence $\left(T^{n_{i}} x\right)$. Then $\xi=\lim _{i \rightarrow \infty} T^{n_{i}} x$ is e periodic point, that is, there is a positive integer $\mathrm{k}$ such that $T^{k} \xi=\xi$

\section{Main Results.}

Definition 3.1.[1] Let $(X, M, *)$ be a fuzzy metric space. A subset $\mathrm{A}$ of $\mathrm{X}$ is said to be $\mathrm{F}$-bounded if and only if there exist $t>0$ and $0<r<1$ such that $M(x, y, t)>1-r$ for all $x, y \in A$.

Definition 3.2. Let $(X, M, *)$ be a fuzzy metric space. For $A \subset X$ we denote the diameter of $\mathrm{A}$ by $\delta(A)$ and $\delta(A)=\inf \{M(x, y, t): x, y \in A, t>0\}$

If $A$ is F-bounded then $\delta(A)>r$ for some $0<r<1$.

Preposition 3.3. Let $(X, M, *)$ be a fuzzy metric space. If for $A, B \subset X$, we have $A \subset B \subset X$ then $\delta(A) \geq \delta(B)$. Let $\left(x_{n}\right)$ be a sequence in fuzzy metric space .

Define $\delta_{i j}\left(\left(x_{n}\right)\right)=\inf \left\{M\left(x_{m}, x_{k}, t\right): m \geq i, k \geq j, t>0\right\} \forall(i, j) \in N^{2}$.

Preposition 3.4. Let $(X, M, *)$ be a fuzzy metric space and $\left(x_{n}\right)$ a sequence in it. If one $\delta_{i_{0} j_{0}}\left(\left\{x_{n}\right\}\right)>r_{0}$ for $0<r_{0}<1$ than for all $\delta_{i j}\left(\left\{x_{n}\right\}\right)$ exist some $r, 0<r<1$ such that $\delta_{i j}\left(\left\{x_{n}\right\}\right)>r$.

Proof. Denote $A=\inf \left\{M\left(x_{m}, x_{i_{0}}, t\right), 1 \leq m \leq i_{0}, t>0\right\}$ and $B=\inf \left\{M\left(x_{k}, x_{j_{0}}, t\right): 1 \leq k \leq j_{0}, t>0\right\}$

Since the sets $\left\{M\left(x_{m,} x_{i_{0}}, t\right), 1 \leq m \leq i_{0}, t>0\right\},\left\{M\left(x_{k}, x_{j_{0}}, t\right): 1 \leq k \leq j_{0}, t>0\right\}$ are finite, than $0<A, B<1$

Let us prove the preposition for $\delta_{11}\left(\left\{x_{n}\right\}\right)$.

For $m \geq i_{0}$ and $k \geq j_{0}$, by (1) we have $M\left(x_{m}, y_{k}, t\right) \geq \delta_{i_{0} j_{0}}\left(\left(x_{n}\right)\right)>r_{0}$.

For $m \geq i_{0} k \leq j_{0}$ we have

$M\left(x_{m}, x_{k}, t\right)>M\left(x_{m}, x_{j_{0}}, \frac{t}{2}\right) * M\left(x_{j_{0}}, x_{k}, \frac{t}{2}\right) \geq \delta_{i_{0} j_{0}}\left(x_{n}\right) * M\left(x_{j_{0}}, x_{k}, \frac{t}{2}\right)>r_{0} * B>0$

For $m \leq i_{0}, k \geq j_{0}$ we have

$M\left(x_{m}, x_{k}, t\right)>M\left(x_{m}, x_{i_{0}}, \frac{t}{2}\right) * M\left(x_{i_{0}}, x_{k}, \frac{t}{2}\right) \geq M\left(x_{i_{0}}, x_{m}, \frac{t}{2}\right) * \delta_{i_{0} j_{0}}\left(\left(x_{n}\right)\right)>A * r_{0}>0$

For $m \leq i_{0}, k \leq j_{0}$ we have

$$
\begin{aligned}
& M\left(x_{m}, x_{k}, t\right)>M\left(x_{m}, x_{i_{0}}, \frac{t}{2}\right) * M\left(x_{i_{0}}, x_{k}, \frac{t}{2}\right) \geq \\
& M\left(x_{i_{0}}, x_{m}, \frac{t}{2}\right) * M\left(x_{i_{0}}, x_{j_{0}}, \frac{t}{4}\right) * M\left(x_{j_{0}}, x_{k}, \frac{t}{4}\right) \geq A * \delta_{i_{0} j_{0}} * B>A * r_{0} * B>0
\end{aligned}
$$

So, We can give $r \in(0,1)$ where $r \leq \min \left\{r_{0}, r_{0} * A, r_{0} * B, r_{0} * A * B\right\}$ and we have $\left.\delta_{11}\left(x_{n}\right)\right)>r$.

But $\delta_{i j}\left(\left(x_{n}\right)\right) \geq \delta_{11}\left(\left(x_{n}\right)\right)>r$ for $i, j \in N$ and $0<r<1$.

Corollary 3.5. Let $(X, M, *)$ be a fuzzy metric space and $\left(x_{n}\right)$ a sequence in it. The sequences $\left(x_{n}\right)$ is bounded if and only if exists a $r \in(0,1)$ such that $\delta_{11}\left(\left\{x_{n}\right\}\right)>r$. 
Theorem 3.6. Let $(X, M, *)$ be a fuzzy metric space and $\left(x_{n}\right)$ a sequence in it. If the sequences $\left(x_{n}\right)$ satisfies the following condition, then it is Cauchy in $(X, M, *)$.

(1) The sequences $\left(x_{n}\right)$ is bounded in $(X, M, *)$ and

$\forall \varepsilon>0, \exists r \in N, \exists \delta \in(0, \varepsilon), \exists \varepsilon<\varepsilon_{0}$ such $\quad$ that $\quad \varepsilon-\delta<\delta_{i j}\left(\left\{x_{n}\right\}\right) \leq \varepsilon \Rightarrow M\left(x_{i+r}, x_{j+r}, t\right) \geq \varepsilon_{0} \quad$ whenever $i, j \in N, t>0$

Proof. Let $\left(x_{n}\right)$ be a sequence in $(X, M, *)$ satisfying (1). Define

$\alpha_{n}=\delta_{n, n}=\inf \left\{M\left(x_{i}, x_{j}, t\right), i \geq n, j \geq n, t>0\right\}$

For $n<m,\left\{M\left(x_{i}, x_{j}, t\right), i \geq m, j \geq m, t>0\right\} \subset\left\{M\left(x_{i}, x_{j}, t\right), i \geq n, j \geq n, t>0\right\}$, so $\alpha_{n} \leq \alpha_{m}$ and the sequence $\left(\alpha_{n}\right)$ is increasing in [0,1]. Hence it converges and $\lim _{n \rightarrow \infty} a_{n}=\sup \left\{\alpha_{n}: n \in N\right\}=a \leq 1$

Suppose that $a<1$. Than exist $\delta \in(0, a)$ and $n_{0} \in N$, such that for $n \geq n_{0}$

$a-\delta<\alpha_{n}=\delta_{n, n} \leq a$

For $i \geq n_{0}, j \geq n_{0}$ denote $k=\max \{i, j\}$ and we have $k \geq n_{0}$ and

$a-\delta<\delta_{n_{0}, n_{0}}\left(\left(x_{n}\right)\right)=\alpha_{n_{0}} \leq \delta_{i j}\left(\left\{x_{n}\right\}\right) \leq \delta_{k, k}\left(\left(x_{n}\right)\right)=\alpha_{k} \leq a$.

From the condition (1) for $\varepsilon=a>0$ there are $r \in N, \delta \in(0, \varepsilon), \varepsilon_{0}>\varepsilon=a$

such that $a-\delta<\delta_{i, j}\left(\left\{x_{n}\right\}\right) \leq a \Rightarrow M\left(x_{i+r}, x_{j+r}, t\right) \geq \varepsilon_{0}$, whenever $i \geq n_{0}, j \geq n_{0}, t>0$

So $\alpha_{n_{0}+r}=\delta_{n_{0}+r, n_{0}+r}\left(\left(x_{n}\right)\right)=\inf \left\{M\left(x_{i+r}, x_{j+r}, t\right): i \geq n_{0}, j \geq n_{0}, t>0\right\} \geq \varepsilon_{0}>\varepsilon=a$

This is a contradiction. So $a=1$.

The inequality $1=\lim _{n \rightarrow \infty} a_{n}=\lim _{n \rightarrow \infty} \delta_{n, n} \leq \lim _{n \rightarrow \infty} M\left(x_{n}, x_{n+p}, t\right) \leq 1$ implies $\lim _{n \rightarrow \infty} M\left(x_{n}, x_{n+p}, t\right)=1$

So the sequence $\left(x_{n}\right)$ is Cauchy.

Let $\left(x_{n}\right)$ and $\left(y_{n}\right)$ be the sequences in a fuzzy metric space. Define $\delta_{i j}\left(\left(x_{n}\right),\left(y_{n}\right)\right)=\inf \left\{M\left(x_{m}, y_{k}, t\right): m \geq i, k \geq j, t>0\right\}$

Theorem 3.7. Let $(X, M, *)$ be a complete fuzzy metric space and $\mathrm{T}$ a continuous self-mapping define on $\mathrm{X}$. If $\mathrm{T}$ satisfies the following condition, than $\mathrm{T}$ has a fixed point $u \in X$.

(1) For all $x, y \in X$, the sequences $\left(T^{n} x\right)$ and $\left(T^{n} y\right)$ are bounded in $(X, M, *)$ and

$\forall \varepsilon>0, \exists r \in N, \exists \delta \in(0, \varepsilon), \exists \varepsilon_{0}>\varepsilon$, such that $\quad \varepsilon-\delta<\delta_{i j}\left(\left(T^{n} x\right),\left(T^{n} y\right)\right) \leq \varepsilon \Rightarrow M\left(T^{i+r} x, T^{j+r} x, t\right) \geq \varepsilon_{0} \quad$ whenever $i, j \in N, t>0$.

Proof. Let $x \in X$. We define the iterative sequence $\left\{x_{n}\right\}$ as follows $x_{n+1}=T x_{n}$, for $n \in N$.

If there exists $n_{o} \in N$ such that $x_{n_{0}}=x_{n_{0}+1}$ than $x_{n_{0}}$ is a fixed point of T. Assume then that $x_{n} \neq x_{n+1}$ for each $n \in N$.

We first shall prove that if T satisfy the conditions (1) the sequence $\left\{x_{n}\right\}$ is a Cauchy sequence.

Substituting $x=x_{n}$ and $y=x_{n+1}$ in (1) we obtain:

the sequence $\left\{x_{n}\right\}$ is bounded in $(X, M, *)$ and

$\forall \varepsilon>0, \exists r \in N, \exists \delta \in(0, \varepsilon), \exists \varepsilon_{0}>\varepsilon$, such that $\quad \varepsilon-\delta<\delta_{i j}\left(\left\{x_{n}\right\}\right) \leq \varepsilon \Rightarrow M\left(T^{i+r} x, T^{j+r} x, t\right) \geq \varepsilon_{0} \quad$ whenever $i, j \in N, t>0$ but $\quad \delta_{i j}\left(\left(x_{n}\right),\left(y_{n}\right)\right)=\inf \left\{M\left(T^{m} x, T^{k} y, t\right): m \geq i, k \geq j, t>0\right\}=\inf \left\{M\left(T^{m+n} x, T^{k+n+1} x\right): m \geq i, k \geq j, t>0\right\}$ $=\inf \left\{M\left(x_{m+n}, x_{k+1+n}, t\right): m \geq i, k \geq j, t>0\right\}=\delta_{i+n, j+n+1}\left(\left(x_{n}\right),\left(y_{n}\right)\right)$ and $M\left(T^{i+r} x_{n}, T^{j+r} x_{n+1}, t\right)=M\left(x_{n+i+r}, x_{n+1+j+r}, t\right)$. 
So the sequence $\left\{x_{n}\right\}$ satisfies condition (1) in theorem 3.5 , so it is a Cauchy sequence in $(X, M, *)$.

By completeness of space $(X, M, *)$, there exists $u \in X$ such that $\left\{x_{n}\right\}$ converges to $u$ and $\lim _{n \rightarrow \infty} M\left(x_{n}, u, t\right)=1$.

We will show that $u$ is the fixed point of T i.e. $M(u, T u, t)=1$. By the continuous of $T$ we can have

$\lim _{n \rightarrow \infty} M\left(x_{n}, u, t\right)=\lim _{n \rightarrow \infty} M\left(T x_{n-1}, u, t\right)=\lim _{n \rightarrow \infty} M(T u, u, t)=1$ and $u$ is a fixed point of T.

Theorem 3.8. Let $(X, M, *)$ be a complete fuzzy metric space, where the continuous t-norm is defined as $a * b=a b(a * b=\min \{a, b\})$ Let $T: X \rightarrow X$ be a self mapping satisfying the following condition

(1) given $\varepsilon>0$, there exists a $\delta \in(0, \varepsilon)$ such that for all $x, y \in X$

$\varepsilon-\delta<m(x, y, t)<\varepsilon \Rightarrow M(T x, T y, t) \geq \varepsilon$

where $m(x, y, t)=\min \left\{M(x, y, t), M(x, T x, t), M(y, T y, t), M(x, T y, 2 t), M(y, T x, t), \frac{M(x, T x, t) M(y, T y, t)}{M(x, y, t)}\right\}$

Then $\mathrm{T}$ has a unique fixed point.

Proof. Let $x_{0} \in X$ be an arbitrary point. Consider the sequence $\left\{x_{n}\right\}=\left\{T^{n} x_{0}\right\}$. We will prove that $\left\{x_{n}\right\}$ is a Cauchy sequence in X. Let $M_{n}=M\left(x_{n}, x_{n+1}, t\right)$, $\mathrm{t}>0$.

If for some $\mathrm{n}, M_{n}=1$ than $M_{n}=M\left(x_{n}, x_{n+1}, t\right)=1$ implies that $x_{n}=x_{n+1}=T x_{n}$ so $\mathrm{T}$ has a fixed point.

Now suppose that $M_{n} \neq 1$ for all $\mathrm{n}$.

If $m(x, y, t)=1$ for some $x, y \in X$ we have that $M(x, T x, t)=1$ and $x=T x$. Hence $\mathrm{x}$ is a fixed point for T.

If $m(x, y, t)<1$ for all $x, y \in X$ than by (1) we have $m(x, y, t)<\varepsilon<M(T x, T y, t)$.

For any $n \in N$

$M_{n}=M\left(x_{n}, x_{n+1}, t\right)=M\left(T x_{n-1}, T x_{n}, t\right)>m\left(x_{n-1}, x_{n}, t\right)$

$=\min \left\{\begin{array}{l}M\left(x_{n-1}, x_{n}, t\right), M\left(x_{n-1}, T x_{n-1}, t\right), M\left(x_{n}, T x_{n}, t\right), M\left(x_{n-1}, T x_{n}, 2 t\right), \\ M\left(x_{n}, T x_{n-1}, t\right), \frac{M\left(x_{n-1}, T x_{n-1}, t\right) M\left(x_{n}, T x_{n}, t\right)}{M\left(x_{n-1}, x_{n}, t\right)}\end{array}\right\}=$

$\min \left\{\begin{array}{l}M\left(x_{n-1}, x_{n}, t\right), M\left(x_{n-1}, x_{n}, t\right), M\left(x_{n}, x_{n+1}, t\right), M\left(x_{n-1}, x_{n+1}, 2 t\right), \\ M\left(x_{n}, x_{n}, t\right), \frac{M\left(x_{n-1}, x_{n}, t\right) M\left(x_{n}, x_{n+1}, t\right)}{M\left(x_{n-1}, x_{n}, t\right)}\end{array}\right\}=$

$\min \left\{M\left(x_{n-1}, x_{n}, t\right), M\left(x_{n}, x_{n+1}, t\right), M\left(x_{n-1}, x_{n+1}, 2 t\right), M\left(x_{n}, x_{n+1}, t\right)\right\}$

Since $M\left(x_{n-1}, x_{n}, t\right) M\left(x_{n}, x_{n+1}, t\right)<M\left(x_{n-1}, x_{n+1}, 2 t\right)$ than

$\left.M_{n}=M\left(x_{n}, x_{n+1}, t\right)>m\left(x_{n-1}, x_{n}, t\right)=\min \left\{M\left(x_{n-1}, x_{n}, t\right), M\left(x_{n}, x_{n+1}, t\right), M\left(x_{n-1}, x_{n+1}, 2 t\right)\right)\right\}>$

$\min \left\{M\left(x_{n-1}, x_{n}, t\right), M\left(x_{n}, x_{n+1}, t\right), M\left(x_{n-1}, x_{n}, t\right) M\left(x_{n}, x_{n+1}, t\right)\right\}=\min \left\{M\left(x_{n-1}, x_{n}, t\right), M\left(x_{n}, x_{n+1}, t\right)\right\}=$

$\min \left\{M_{n-1}, M_{n}\right\}=M_{n-1}$

Thus the sequence $\left\{M_{n}\right\}$ is strictly increasing. Since $\left\{M_{n}\right\} \subset[0,1]$ then $\left\{M_{n}\right\}$ converges to some $s \in[0,1]$, where $s=\sup \left\{M_{n}\right\}$.

If $s<1$ than exists $\delta>0$ and $m \in N$ such that for $n>m, s-\delta<M_{n-1}=M\left(x_{n-1}, x_{n}, t\right) \leq s$. By the condition (1) and (2), we have 
$s-\delta<M_{n-1}=m\left(x_{n-1}, x_{n}\right) \leq s \Rightarrow M\left(T x_{n-1}, T x_{n}, t\right) \geq s$

But $M\left(T x_{n-1}, T x_{n}, t\right)=M\left(x_{n}, x_{n+1}, t\right)=M_{n} \geq s$, that is a contradiction. So $s=1=\lim _{n \rightarrow \infty} M\left(x_{n}, x_{n+1}, t\right)$.

For $k \in N, M\left(x_{n}, x_{n+k}, t\right)>M\left(x_{n}, x_{n+1}, \frac{t}{k}\right) M\left(x_{n+1}, x_{n+2}, \frac{t}{k}\right) \ldots M\left(x_{n+k-1}, x_{n+k}, \frac{t}{k}\right)$ and

$\lim _{n \rightarrow \infty} M\left(x_{n}, x_{n+k}, t\right)=1$. So the sequence $\left\{x_{n}\right\}$ is Cauchy sequence in $(X, M, *)$.

By completeness of space $(X, M, *)$, there exists $u \in X$ such that $\left\{x_{n}\right\}$ converges to $u$ and $\lim _{n \rightarrow \infty} M\left(x_{n}, u, t\right)=1$.

We will show that $u$ is the fixed point of Ti.e. $M(u, T u, t)=1$.

$M\left(T x_{n}, T u, t\right) \geq m\left(x_{n}, u\right)=\min \left\{\begin{array}{l}M\left(x_{n}, u, t\right), M\left(x_{n}, T x_{n}, t\right), M(T u, u, t), M\left(x_{n}, T u, 2 t\right), \\ M\left(T x_{n}, u, t\right), \frac{M\left(x_{n}, T x_{n}, t\right) M(T u, u, t)}{M\left(x_{n}, u, t\right)}\end{array}\right\}$

Taking the limit as $n \rightarrow \infty$, we have $M(u, T u, t)>M(u, T u, t)$, a contradiction. Therefore $M(u, T u, t)=1$ and $u=T u$.

To show the uniqueness, we assume that $z$ is another fixed point of $\mathrm{T}$. If $M(z, u, t)<1$, from (2) it follows that

$$
M(z, u, t)=M(T z, T u, t)>m(z, u, t)=\min \left\{\begin{array}{l}
M(z, u, t), M(z, T z, t), M(T u, u, t), M(z, T u, 2 t), \\
M(T z, u, t), \frac{M(z, T z, t) M(T u, u, t)}{M(z, u, t)}
\end{array}\right\}
$$

$=\min \left\{\begin{array}{l}M(z, u, t), M(z, T z, t), M(T u, u, t), M(z, T u, 2 t), \\ M(T z, u, t), \frac{M(z, T z, t) M(T u, u, t)}{M(z, u, t)}\end{array}\right\}=M(z, u, t)$

which is a contradiction. Then $M(z, u, t)=1$ and $z=u$. This proves the uniqueness of the fixed point and completes the proof of the theorem.

Remark 3.9. The mapping in theorem is not necessary to be continuous.

\section{REFERENCE}

[1] A. George and P. Veeramani, On some results in fuzzy metric spaces, Fuzzy sets and Systems, 64, (1994) 395-399.

[2] A. Meir and E. Keeler, A theorem on contraction mappings, J.Math.Anal.Appl. 28(1969), 326-329.1,3

[3] A. Razani, A contraction theorem in fuzzy metric spaces, Fixed point theory and Applications, vol 2005, no. 3, pp 257265

[4] I. Kramosil and J.Michalek, Fuzzy metric and statistical spaces, kybernetica, 11, (1975) 336-344.

[5] J. Jachymski, Equivalent conditions and the Meir-Keeler type theorems, J.Math.Anal.Appl. 194, (1995), 293-303.1

[6] J. Matkowski, Fixed point theorems for contractive mappings in metric spaces, Casopis Pro Pestovani Matematiky. 105 94), (1980), 341-344.1

[7] K. Menger, Statistical metrics, Proc. Nat. Acad. sci. (USA), 28 (1942), 535-537

[8] L.A.Zadeh, Fuzzy sets, Inform. and Control., 8 (1965), 338-353

[9] Lj. B. Ciric, A new fixed point theorem for contractive mappings, Publ. Inst. Math. (Beograd) 30(44), (1981), 25-27.1

[10] M. Akkouchi, A Meir-Keeler type common fixed point theorems in four mappings, Opuscula Mathematica, 31 (1) (2011), 5-14.

[11] M. Grabiec, Fixed point in fuzzy metric spaces, Fuzzy sets and Systems, 27 (1988), 385-389.

[12] S. Heilpern., Fuzzy mappings and fixed point theorems, J.Math. Anal.Appl., 83 91981), 566-569. 


\section{Author's ProfiLe}

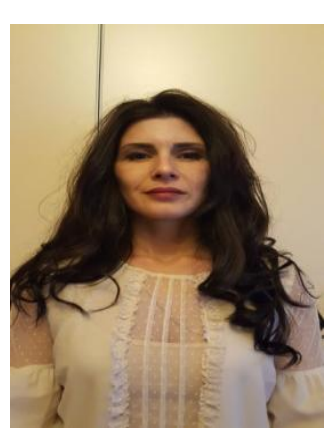

M.Sc. Siditë Duraj (DOB-19/09/1980)

Completed her M.Sc. in Mathematics at Tirana University in 2011 , she is a Ph. D student. She works as a lecturer at Shkodra University, in the Department of Mathematics, Faculty of Natural Science, Albania for more than 5 years. Her subject of teaching is Mathematical Analysis and Functional Analysis. Her research field is Functional Analysis.

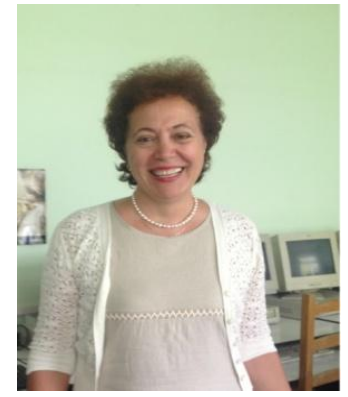

Dr. Elida Hoxha (DOB-08/01/1961)

Completed her M.Sc. in Mathematics from Tirana University in the year 1984 and completed her Ph.D. from Tirana University in 1997. She has a teaching experience of more than 29 years. Currently she is working as a Professor in the Department of Mathematics, Faculty of Natural Science, University of Tirana, Albania.

She is a popular teacher in under graduate and post graduate level. Her subject of teaching is Mathematical Analysis, Topology, Functional Analysis. Besides teaching she is actively engaged in research on the fields of Fixed Point Theory, Fuzzy sets and Fuzzy mappings, Topology. 